\title{
NOTAS SOBRE LA TRANSICIÓN DESDE LA IDEA MATERIALISTA DEL ESTADO
}

\author{
Pablo Huerga Melcón \\ Universidad de Oviedo
}

\begin{abstract}
Resumen.- Se analiza el papel de la filosofía marxista en el proceso de transformación del Estado español desde el inicio de la transición. Tomando como referencia la interpretación de la idea de Estado que ofrecen autores como Manuel Sacristán, o Jaime Pastor. Concretamente, cómo la idea de la eliminación del estado ha ido configurando un proceso de privatizaciones que ha resultado determinante en el debilitamiento objetivo del estado.
\end{abstract}

Palabras clave: Teoría del estado, Marxismo, filosofía política, Materialismo filosófico, Transición, España.

\section{Notes on the transition from the state materialist idea}

\begin{abstract}
The role of Marxist philosophy in the process of transformation of the Spanish State since the beginning of the transition is analyzed. Taking as reference the interpretation of the idea of State offered by authors such as Manuel Sacristán, or Jaime Pastor. Specifically, how the idea of the elimination of the state has been configuring a privatization process that has been decisive in the objective weakening of the state.
\end{abstract}

Keywords: State theory, Marxism, political philosophy, philosophical materialism, transition, Spain.

\section{El Materialismo filosófico como filosofía de la Transición}

La Transición española a la democracia es, desde luego, un tópico en la literatura politológica actual. Por su cercanía, sigue siendo motivo de discusión, aunque el consenso alcanza a su propia interpretación. Según este consenso España vivió un tránsito modélico a la Democracia con mayúsculas. Hubo resistencias de los extremos radicales, pero se han superado con una moderación ejemplar. Delimitar el período comprendido como la Transición también resulta muy complicado, tal parece que estamos aún en ella, y seguramente es asi, al menos por la inestabilidad que se respira en la política nacional, sin embargo, creo que no sería inapropiado concebir la transición como el período que se abre y se cierra con la monarquía de Juan Carlos I. Seguramente su reinado se superpone con el mismo proceso de transición española, salvo que el nuevo período del reinado de Felipe $\mathrm{VI}$ desemboque en un cambio de régimen, en una República por ejemplo, en cuyo caso cabría entender como Transición todo el período abierto desde la herencia monárquica de Franco, hasta la instauración de una III República. Pero, de momento, podríamos delimitarlo con el fin del reino de Juan Carlos I.

Mi perspectiva es la de un español que vivió estos años de transición "en sus propias carnes". La muerte de Franco me cogió con 9 años. Fue mi madre quien me sentó ante el televisor para ver a Arias Navarro transmitir la noticia del 
fallecimiento de Francisco Franco, el Gran Dictador. En el pueblo, los vecinos se pasaron los días viendo por la televisión la interminable cola de españoles que iban a despedir a Franco. Una cosa que siempre me sorprendió y nunca he olvidado es que este político muriera atendido en un hospital público, el de La Paz. En eso, las cosas sí han cambiado. Al rey lo hemos visto siempre ir a las clínicas más pijas y privadas de Madrid. Por lo demás, yo estudié en Universidades Laborales, de modo que para mí España era un país muy bien organizado y con una capacidad impresionante para gestionar recursos. No obstante, el hecho de haber vivido en ese momento histórico no da seguramente ningún privilegio para comprenderlo. De hecho, la impresión que hemos tenido de la Transición a través de los medios de comunicación no puede haber sido más confusa, más acomodaticia, ni más mediatizada. Revisando alguna literatura de la época, se observa cómo las categorías históricas de análisis dirigen machaconamente los acontecimientos por sendas interpretativas estériles que no hacen más que oscurecer el fenómeno.

Se hace necesario, pues, tomar como referencia algún sistema de ideas que permita organizar este fenómeno histórico y comprenderlo desde una perspectiva crítica, capaz, entre otras cosas, de organizar y comprender en su dimensión histórica, política y geoestratégica, los acontecimientos que conforman lo que históricamente se ha dado en llamar la Transición española. Nosotros tomamos como referencia el Materialismo filosófico de Gustavo Bueno, un sistema filosófico surgido a su vez en el mismo trasiego de la transición española, siendo posible pues afirmar que Gustavo Bueno es el filósofo español de la Transición. De hecho, aunque este sistema filosófico trasciende el marco histórico concreto en el que surge no puede dejar de tomarse en consideración el hecho de que efectivamente este sistema de ideas ha surgido y se ha alimentado de las propias contradicciones y de los numerosos acontecimientos y conflictos que han tenido lugar en España en el proceso de despliegue de la democracia constitucional monárquica que nace en 1975. Todas las obras de Gustavo Bueno, además de proyectarse como un sistema de ideas filosóficas, han nacido en el contexto de los conflictos presentes y actuales que, sin duda, iban planteándole a Bueno nuevos retos filosóficos. Las obras de Bueno han nacido en medio de la batalla por las ideas, porque la Transición ha sido, también, una batalla permanente por las ideas, y en ella ha demostrado que el trabajo filosófico riguroso puede dar frutos magníficos.

Bueno ha escrito desde las trincheras, siempre contra las tendencias y las modas, contra la pereza intelectual, contra la impostura y contra la traición; ha trabajado tomando como referencia a España, y su pensamiento ha sido siempre un pensamiento político rigurosamente marcado por la problemática que la Transición española ha puesto ante la disciplina filosófica. Así pues, es un privilegio disponer de este arsenal magnífico de ideas y, desde luego, un reto inabarcable para cualquiera, tratar de comprender y articular cómo ese arsenal filosófico ha ido jalonándose en la lucha diaria y en el compromiso permanente con España y su situación histórica y política en el mundo tal y como se define en este presente histórico. Sin duda, por otro lado, creo que se puede decir que el Materialismo Filosófico de Gustavo Bueno no sería como es de no haber mediado en su despliegue ideológico, la insistente premura de la acción política, del compromiso y la responsabilidad que ha suscitado la llamada "Transición española a la 
democracia". Y a su vez, no creo que sea posible alcanzar una comprensión completa y seria de la Transición sin haber estudiado a fondo la obra de Gustavo Bueno, pero no como un fenómeno más de la transición, sino como quizá el único sistema de referencia capaz de permitir comprender y articular el panorama filosófico e ideológico español como efectivamente un entramado de fenómenos todos ellos determinados y terminados en su propio papel como actores de la Transición.

\section{El marxismo entiende el Estado desde una perspectiva metafísica}

Las categorías que suelen usarse para comprender la transición se nutren, a nuestro parecer, de una importante confusión ideológica, procedente principalmente de la ideología marxista, más concretamente de una interpretación de la idea de Estado que podemos considerar, desde la perspectiva del materialismo filosófico, como una interpretación metafísica. Consideramos metafísica esta interpretación marxista del Estado porque se entiende el Estado como una coyuntura histórica que está necesariamente al servicio de las clases poseedoras y cuyo origen y sentido radica solamente en esa condición de instrumento de represión de las "clases populares", o del proletariado. Un instrumento al servicio de la lucha de clases que, necesariamente, debe ser derribado en el final de la historia de la humanidad. Así lo decía, por ejemplo, Jaime Pastor, en 1977, en plena transición española, en un texto titulado precisamente así, El estado': "El Estado surgió en el momento de la aparición de las clases y no tiene por lo tanto ningún carácter "natural" sino que deberá "extinguirse" cuando desaparezcan las clases"2.

Según Pastor el Estado tiene siempre por definición un "carácter conservador" y represivo y el fin último de la revolución socialista debe ser la extinción del Estado como tal: "Como señalan Marx y Engels, la diferencia con los anarquistas no se halla en el deseo de que el Estado desaparezca sino en la consideración de la necesidad de una época de transición que permita esa desaparición. Así, frente a la "abolición" por decreto del Estado propugnada por los anarquistas, Marx y Engels defendieron la creación de un nuevo Estado que, sobre las ruinas del viejo aparato estatal burgués, la transición a una sociedad sin clases en la cual el Estado no sería "abolido", o suprimido, sino que se "extinguiría" como tal."3

Como se ve, estamos ante una idea metafísica y, por tanto, confusa de la idea de Estado, pues se considera que es un instrumento de algún modo "creado" en el proceso de represión de una clase por otra, tal que sólo su abolición puede dar lugar a la desaparición de la lucha de clases, pero al mismo tiempo se considera que su estructura es esencialmente la misma en todo tiempo y lugar, y no cabe reforma alguna. "Porque la particularidad de la revolución proletaria es la de que, por ser la clase obrera una clase destinada a desaparecer, no puede heredar el viejo aparato de Estado, reflejo de una sociedad de clases y por tanto incapaz de

\footnotetext{
1 Jaime Pastor, El estado, editorial Mañana, Madrid 1977. He visto en Wikipedia que Jaime Pastor está actualmente en el Consejo Ciudadano de Podemos, partido del que es también uno de los fundadores.

2 Jaime Pastor, Op. Cit., pág. 29.

3 Jaime Pastor, Op. Cit., pág. 31.
} 
abrir la vía hacia una nueva sociedad. El momento de la crisis revolucionaria ha de servir a los trabajadores, no para someterse a la "soberanía" de las instituciones del Estado burgués sino, al contrario, para crear otras nuevas basadas en la representación directa de la población." 4

\section{No es posible una representación directa de "la población" en el Estado}

Según este enfoque, lo esencial del Estado (que siempre habrá de ser burgués, puesto que está al servicio de la lucha de clases) es el hecho de que no hay representación directa de la población, sino el ejercicio del poder por una minoría. Aunque estos análisis resultan ser demasiado simples, recogen también la idea básica de la ideología marxista que lleva incluso a Marx a denunciar en el Programa de Gotha la escuela pública como instrumento de represión de las clases dominantes 5 . Aquí está una clave importante para comprender todo el confusionismo ideológico marxista acerca del Estado. El mismo Manuel Sacristán, en su famoso panfleto por la eliminación de la enseñanza de la filosofía, defendía efectivamente que la eliminación de la filosofía en la enseñanza universitaria es un factor necesario para la eliminación del propio estado, porque, según él, la enseñanza de la filosofía está al servicio de los intereses del estado burgués ${ }^{6}$. Es curioso, sin embargo, notar que una vez criticado por reduccionista Sacristán en su alegato contra la filosofía, cuando el Gobierno de Zapatero se inventa aquella asignatura de Educación para la ciudadanía, el propio Bueno sale a la palestra criticando dicha propuesta por ser una herramienta de domesticación por parte de las instituciones del Estado, y por tanto, al servicio de sus intereses ideológicos, como si la asignatura de Educación para la ciudadanía condujera necesariamente a la formación de individuos en lo que Bueno llamaba el "Pensamiento Alicia", algo tan absurdo, como absurdo era por parte de Manuel Sacristán alegar contra la Filosofía porque según él sólo servía para transmitir el espíritu nacional franquista y la filosofía escolástica y tomista que lo sustentaba. Absurdo sobre absurdo. Pero si el fin de la filosofía era necesario para el fin del Estado, según Sacristán, la eliminación de la enseñanza de la filosofía no traería mayores consecuencias políticas, lo que obviamente es más sensato, aunque no sé por qué necesariamente debe ser mejor que no se enseñe filosofía, como también ahora desea el -dicho con todos los respetos- desorientado Gabriel Albiac.

Atengámonos por el momento al asunto de la representación del "pueblo" en el Estado. Es lógico que el Estado surja como instrumento para el ejercicio del poder de unos grupos sobre otros, pero no porque ello sea efectivamente una alternativa

\footnotetext{
4 Jaime Pastor, Op. Cit., pág. 30.

5 Jaime Pastor lo simplifica muy bien: "Un ejemplo claro -dice- de lo que significan estos cambios se halla en la crisis de la escuela y de la Universidad: obligadas a transmitir un saber cada vez más desvirtuado por los valores burgueses dominantes y por la necesaria formación de una fuerza de trabajo adecuada a las necesidades de producción, se encuentran cada vez más sometidas a los imperativos de rentabilización capitalista y del control estricto del Estado." (pág. 17).

6 Véase nuestro ensayo, "Notas para un análisis materialista de la noción de Filosofía de Manuel Sacristán", en El Catoblepas, n 48 (febrero de 2006). http://www.nodulo.org/ec/2006/n048p13.htm. 7 Gustavo Bueno, Zapatero y el Pensamiento Alicia. Un presidente en el País de las Maravillas, Temas de Hoy, Madrid 2006
} 
posible desde el punto de vista no solo político sino incluso antropológico. Efectivamente los estados se caracterizan por eso no por azar, ni por razones estrictamente sociológicas, ni por la prevalencia de los intereses de clase, sino que todo ello es posible precisamente porque las condiciones materiales de las sociedades en las que va fraguando esta nueva forma de organización social que llamamos Estado son tales que es materialmente imposible eso que Jaime Pastor llama la "representación directa de la población", o la llamada "democracia directa". Y ello no solamente porque estamos ante un aumento particular de la población, elemento sin duda fundamental, sino porque la propia sociedad aparece organizada de un modo más complejo y diverso desde el punto de vista de la producción social de la vida. De modo que es precisamente esta forma nueva de organización de las sociedades que llamamos los estados, la que ha permitido la conformación de sociedades cada vez más complejas, capaces de albergar un número creciente de población que puede sobrevivir en dichas condiciones precisamente porque existe algún tipo de mecanismo de redistribución de la riqueza, mecanismo que, materialmente, define precisamente al estado, frente a modelos sociales anteriores. Y ello nos obliga, necesariamente, a hacer referencia a esa supina tontería que es lo que en los términos marxistas clásicos se llama el "comunismo primitivo".

\section{El comunismo primitivo como nota resultante de la idea metafísica de Estado}

El comunismo primitivo no sería más que una forma de organización social previa al estado "basado en un escaso desarrollo de las fuerzas productivas", se dice. Pero si el comunismo primitivo se entiende como un tipo de organización social en el que no hay prácticamente desarrollo de las fuerzas productivas, no sé qué añade a ello el llamarlas comunismo, y menos aun si lo que las caracteriza como comunismo es esto: "En la sociedad primitiva no existía el Estado. Ese tipo de sociedad, basada en la caza y la agricultura rudimentaria -con relaciones de producción que partían de la organización cooperativa del trabajo-, se regía sobre la base de una democracia "gentilicia" (de la "gens"), es decir, de un funcionamiento democrático del conjunto de la comunidad. Las funciones administrativas eran realizadas por todos los ciudadanos: todos ellos llevaban armas, todos participaban en las asambleas, las cuales decidían sobre todo lo concerniente a la vida colectiva y a las relaciones de la comunidad con el exterior. Del mismo modo los conflictos internos eran resueltos por el conjunto de los miembros."8

Ese comunismo por ser primitivo es irrecuperable, y precisamente han sido las sociedades complejas, por su propia estructura, las que lo hacen absolutamente imposible. Pero tampoco eso merece consideraciones positivas acerca de las sociedades pre-estatales. Ya Marvin Harris estudió con atención "los asesinatos en el paraíso" 9, aludiendo al hecho de que las sociedades pre-estatales se caracterizan por procesos de control de la población muy eficaces pero intratables desde el punto de vista ético. No obstante, el hecho es que sólo cuando determinadas sociedades primitivas comienzan a desarrollar

8 Jaime Pastor, Op. Cit., pág. 9.

9 Marvin Harris, Caníbales y Reyes, Alianza editorial, Madrid 2011. 
procedimientos de supervivencia del grupo ajenos a los controles de población basados en el infanticidio selectivo o en el gerontocido sistemático, comienzan a crecer y en su acumulación material se van conformando las condiciones materiales para la organización de formas de vida más complejas desde el punto de vista material.

Y es ahí donde debe situarse el Estado, no solamente visto como instrumento al servicio de las clases dominantes, sino al contrario. Surgen clases dominantes porque existe ya una organización social suficientemente compleja como para ser articulada mediante el ejercicio del poder por parte de unos grupos frente a otros. Precisamente porque los grupos son divergentes. Aunque el Estado efectivamente ha sido un instrumento de dominación entre grupos, no por ello podemos reducir el Estado a esa función. Más allá de ese enfoque reduccionista, debe entenderse como una estrucfura organizativa capaz de permitir el aumento de población y por tanto el desarrollo de la diversificación de los procesos productivos y de las fuerzas prodúctivas de la sociedad, así como el aumento y complejización de las contradicciones. De hecho, el carácter fundamental de una sociedad política según la teoría de Gustavo Bueno 10, radica en el hecho de que está constituida por grupos divergentes, siendo la política el arte de hacer posible la articulación del orden social en medio de esta complejidad de intereses contrapuestos. Y, aunque efectivamente los estados proceden de un modo esencialmente amoral en lo que se refiere a la consecución de sus propios fines, particularmente su conservación en el tiempo (su eutaxía, en palabras de Bueno), también puede decirse que el conflicto entre el individuo y la sociedad, entre los fines personales y los planes generales de la sociedad sólo en el Estado comienza a resolverse sin la conculcación de aquellos fines y, por tanto, podemos decir que sólo en el ámbito de esta nueva figura antropológica y ontológica que es el Estado, como modo de organización de las sociedades humanas (de algunas, no de todas), cabe el surgimiento de lo que llamamos la Ética, frente a la Moral. Puesto que es a través del Estado con todas sus contradicciones, como surge la reflexión sobre el conflicto entre los fines personales y los planes generales de la sociedad, y la propia posibilidad de establecer trayectorias divergentes dentro de la sociedad.

Hablamos de Ética y Moral en un sentido materialista también"1. Ética se refiere al conjunto de disposiciones orientadas a la supervivencia del individuo, mientras que la Moral se refiere a los grupos, de manera que las virtudes éticas pueden entrar, y entran necesariamente, en conflicto con las virtudes morales. La virtud ética por excelencia es la Fortaleza, que se manifiesta como "Firmeza" cuando se refiere a la virtud que dirige la vida de un individuo para conservarse en el tiempo, y como "Generosidad", que se refiere a la virtud que dirige la vida de un individuo cuando busca la conservación de la vida de sus semejantes. La profesión ética por excelencia sería la Medicina. Sin embargo, en la Moral la virtud de la Fortaleza se refiere a la conservación del grupo, lo que en muchos casos puede suponer el sacrificio de los individuos, contradiciendo los principios de la Ética. El conflicto entre Ética y Moral surge en el ámbito de las Ciudades, de los Estados, donde los

\footnotetext{
10 Véase, Gustavo Bueno, Primer ensayo de las categorías de las "ciencias políticas", Biblioteca Riojana, Logroño 1991. http://www.fgbueno.es/gbm/gb91ccp.htm

11 Para estas cuestiones, consultar la obra de Gustavo Bueno, El sentido de la vida. Seis lecturas de filosofía moral, Ed. Pentalfa, Oviedo 1996. http://fgbueno.es/gbm/gb96sv.htm
} 
fines personales pueden entrar en conflicto con los planes generales de la sociedad y desarrollarse dentro de ella. En las sociedades naturales, por así decir, los fines personales siempre aparecen subordinados a los planes generales de la sociedad, a la supervivencia del grupo, de ahí que prácticas como el infanticidio o el gerontocidio sistemático son síntoma de que estamos todavía en el seno de sociedades pre-estatales, dirigidas por los principios de la Moral. Y cuando estas prácticas, por ejemplo, comienzan a ponerse en entredicho es precisamente porque el conflicto entre el individuo y el grupo comienza a tener cabida, y es posible la modificación de las costumbres mediante las leyes escritas, etc.

De modo que el Estado aparece como una forma de organización social más compleja que surge de la propia canalización de los conflictos, de manera que no solamente es una estructura que reprime y explota, favorece a las clases poseedoras, etc. sino que a su vez, es el marco necesario para la conformación de los ideales políticos, para la lucha de clases, y para el surgimiento y defensa de los ideales políticos más diversos. Es una plataforma objetiva que permite canalizar las fuerzas transformadoras y el nacimiento y despliegue de los ideales políticos más eleyados. Una plataforma que marca precisamente los límites ideológicos posibles de la política: el límite de la disolución del Estado, que ahora podemos ver como la disolución de la plataforma en la que es posible la configuración de los ideales políticos que regulan el conflicto permanente entre individuos y sociedad, y el límite de un estado "totalitario" que regularía la vida de los individuos conforme a los principios de la moral. Ambos límites son, en rigor, humanamente imposibles, son ideales de la razón, ideas reguladoras de imposible ejecución por el carácter conflictivo y anómalo de la vida de los pueblos. Porque no hay posibilidad objetiva de que un Estado pueda someter a la población sistemáticamente a la neutralización de sus fines personales, en una sociedad compleja, por más sistemática y expeditiva que sea la eliminación física de todo disidente posible (hoy en Turquía se aspira a una limpieza de estas características), y porque en una sociedad compleja es imposible el anarquismo sistemático.

Tal vez otros modelos híbridos, que recojan apariencias de los dos límites aquí señalados están en la mente de los poderosos: en la película Wall-E de Andrew Stanton (EEUU, 2008), por ejemplo, se habla de un mundo así organizado, también en Un mundo feliz de Huxley, no así en 1984 de George Orwell, aunque el ideal con el que culmina la novela parece obedecer a ese mismo proyecto: un modelo en el que la población entienda su existencia como totalmente libre, pero cuya realidad es estar sometidos a un poder omnímodo y basado en el abastecimiento sistemático de un soma que puede ser sexual, tecnológico, o una mezcla que contribuya a la idiotización de la sociedad. Algo parecido a los rebaños de animales bípedos implumes de El Político de Platón. Pero, es evidente que ese tipo de sociedad no sería ya una sociedad humana en el sentido político, y nuevamente, consideramos que se trata de un exabrupto de la imaginación. No obstante, las tecnologías de los big data que investigan con pasión en el MIT están abriendo horizontes muy interesantes, como por ejemplo, la posibilidad de regular la vida de los individuos más allá de la voluntad consciente ejercida en las urnas, a partir de los datos estadísticos resultantes de las decisiones cotidianas que los individuos toman, a pesar o contra su propia voluntad o ideario político. Pero esto 
es otro asunto que requiere un estudio particular y que convendría que se convirtiera en objeto de investigación sistemática por algún doctorando español.

\section{Sobre el origen del Estado}

De hecho, como hemos analizado ya en otro lugar12, el origen del Estado puede identificarse como aquella situación social en la que ya es posible la acumulación de trayectorias personales divergentes en la sociedad sin que ello "te cueste la vida" -por así decirlo. Y por tanto, el estado, las ciudades, constituyen un entramado institucional suficientemente complejo como para albergar dentro de sus límites trayectorias personales divergentes, conflictos sociales que no pueden resolverse absolutamente mediante los procesos represivos, aunque sin duda se utilicen sistemáticamente, pero teniendo en cuenta que estos procesos represivos dejan de ser completamente eficaces, si se quiere decir así. Frente a las sociedades pre-estatales, cuya nota particular consiste en delimitar de modo irrevocable las trayectorias personales de cada individuo en su función social, de manera tal que resulta imposible para cualquier individuo contravenir las costumbres establecidas. El conflicto entre el campo y la ciudad estudiado por muchos marxistas, recoge algunos aspectos de esta división esencial entre la vida pre-estatal y la vida estatal o en ciudades.

El estado no es natural, pero tampoco, por ser cultural, es menos necesario, de la misma manera que lo es la rueda, o la palanca. Es un artefacto resultante de la propia complejidad de determinadas sociedades. De manera que invocar hoy por hoy el fin del Estado sólo puede hacerse por una aspiración a recuperar utópicamente el comunismo primitivo -cosa absurda-, o bien dando por hecho que el estado se desvanecerá de por sí en una especie de sopa germinal de seres humanos interconectados. Si además a eso añadimos que el proceso de desaparición del estado debe ser mundial, según la tesis procedimental del marxismo, pero surgiendo a partir de un estado que comience él mismo por autoinmolarse, resulta de todo punto absurdo concebir así la cuestión, habida cuenta de que la prudencia política nunca llevará a una nación a auto-disolverse esperando que las demás hagan lo mismo. Lo que harán las demás naciones será absorber a la nación que se disuelve, y sin problemas. Es lo que ocurre con España y sus independentismos periféricos. El hecho de que existan grupos divergentes en el Estado es sin duda síntoma del vigor de nuestro estado, pero también un peligro, porque requiere precisamente de un arte de la política muy afinado. Cuando Cataluña pretendió independizarse en la Segunda República lo hizo entregándose a Gran Bretaña, y lo mismo hizo el País Vasco (esto lo estudia muy bien, por ejemplo, Enrique Moradiellos en su impresionante biografía de Juan Negrín ${ }^{13}$ ). De la misma manera que ahora el nuevo independentismo catalán pretende entregar la defensa de su territorio al ejército francés, a cambio de dinero. La URSS, perfectamente consciente de estas contradicciones no solamente no se inmoló en aras de la revolución mundial, sino que practicó un patriotismo magnífico que le dio la victoria en la Segunda Guerra Mundial, denominada en la URSS, con toda la

$12 \square$ Pablo Huerga Melcón, "Nota para una fundamentación antropológica de la Globalización" en Eikasia: revista de filosofía, №. 52, 2013, págs. 133-142. http://www.revistadefilosofia.org/52-09.pdf 13 Enrique Moradiellos, Don Juan Negrín, Ed. Península, Barcelona 2006 
razón, la Gran Guerra Patriótica. El éxito del socialismo cubano y de la ideología política de Fidel Castro está en su patriotismo sin fisuras. Los Estados no es que sean naturales, es que son la forma natural de organización de una sociedad compleja, compuesta de grupos divergentes que hay que integrar y dirigir por medio del arte de la política. De hecho, es en el seno del estado en el que ha surgido todo el conjunto de ideas (justicia, igualdad, libertad, autonomía, soberanía, patria, internacionalismo, humanidad) que han contribuido a transformar y reorganizar la vida de los hombres conforme a normas, como forma de regulación del conflicto sistemático que lo caracteriza entre los fines personales y los planes generales de la sociedad, que es lo que constituye, más allá de la lucha de clases, el verdadero motor de la historia ${ }^{14}$.

\section{Sobre la metafísica separación entre Estado y Sociedad}

Otro de los argumentos que sitúa esta idea de Estado en el terreno de la metafísica monista, es el hecho de que se interpreta como una entidad, una institución "separada" formalmente de la "sociedad". De hecho, así comienza el propio Jaime Pastor su libro: "El Estado, en tanto que institución separada respecto al resto de la sociedad que asume unas funciones propias, es producto de la división social del trabajo, de la aparición de las distintas clases sociales." 15 La cuestión es qué puede significar Estado como institución separada de la sociedad, o cómo es concebible una sociedad "dividida en clases", al margen del Estado. Es un absurdo, porque el Estado es la forma en que una sociedad compleja, dividida en clases, se organiza para dar cabida a esa misma complejidad. No hay un Estado al margen de la sociedad política en la que surge, sino que el Estado es una forma de organización de las propias sociedades cuando alcanzan un grado de complejidad creciente, esto es, cuando comienzan a surgir grupos divergentes en conflicto. Entenderlo como algo separado es concebir el Estado como un aparato represor, o entender la sociedad como compuesta de lo que ahora se llama "la ciudadanía", o "el pueblo", como si el pueblo no estuviera conformado por distintos relieves y capas, articuladas entre sí y conformando un Estado. Qué puede significar una sociedad sin estado: sería solamente una masa informe de sujetos, y ahí está precisamente un error fundamental del análisis no del marxismo, sino de estudios como este de Pastor. $\dot{\imath} \mathrm{O}$ tal vez se refiere al hecho de que por naturaleza los hombres tienden a organizarse conforme al patrón del comunismo primitivo y que precisamente cuando unos malvados se hacen con el poder imponen a esa sociedad que naturalmente tiende al comunismo, un orden extraño, artificial, ajeno y totalmente injusto? De ahí que tuego se entienda como una posibilidad real la eliminación del Estado. Sin embargo, este planteamiento tan ingenuo es el que se desprende de la ideología del buen salvaje de Rousseau, que no tiene, por supuesto, mayor recorrido, a día de hoy, por lo que no vamos a discutirlo más.

Sólo si entendemos el Estado como una entidad independiente de la Sociedad, es posible concebir la idea marxista y anarquista en función de la cual se entiende que el fin último de la revolución socialista es la eliminación del estado, o como

14 Véase nuestro ensayo, El fin de la educación, ed. Eikasía, Oviedo 2009.

15 Op. Cit., pág. 9. 
dice Pastor citando el Anti-Dühring de Engels: "Ia vía de solución de las nuevas contradicciones que surgen será la de la aceleración de las condiciones de desaparición de las clases con el fin de que el Estado se "extinga" progresivamente y "en lugar del gobierno sobre las personas aparezca la administración de las cosas y la dirección de los procesos de producción (Engels, "Anti-Dühring"|"16. Pero esto significa que estaríamos ante un tipo de relaciones entre Estado y Sociedad que llamamos, desde la perspectiva del materialismo filosófico, como yuxtaposición metamérica, según la teoría de los conceptos conjugados que ha desarrollado Gustavo Bueno ${ }^{17}$. En ella, la sociedad "civil" se enfrenta a otra estructura institucional, el Estado, que reprime, somete, explota y asfixia la libertad de los puéblos. Pero esta concepción adolece precisamente de una concepción metafísica monista del Estado y de una concepción también monista y metafísica de la sociedad. Sin embargo, eso no significa que no se pueda hablar del Estado como idea filosófica, o de la Sociedad. Diríamos que entre Estado y Sociedad habría que ensayar distintas formas de comprensión de sus relaciones, lo que permitiría organizar distintas teorías acerca del Estado.

Si el Estado es la forma que adquieren distintas sociedades a lo largo de la historia en función de su propio crecimiento demográfico que requiere y supone no solamente la división del trabajo sino la aparición de todo tipo de estructuras jerárquicas y organizativas y la división de la sociedad en clases, estamentos, grupos, etc., entonces sería posible tratar de analizar las relaciones entre Estado y Sociedad en términos de su composición diamérica, teniendo en cuenta que la Sociedad no es solamente una masa de individuos atómicos, sino una estructura compleja compuesta de partes, familias, grupos de presión, gremios, partidos, fratrías, etc., y teniendo en cuenta también que los Estados están compuestos de partes, instituciones, funcionarios, etc. La articulación diamérica de las partes componentes de la sociedad y las partes componentes del estado permite comprender que los estados son esencialmente la forma en la que se articula una sociedad compleja. Y a su vez, que esa forma de organización ha podido pasar por diferentes fases en función de diferentes factores, como son la población, el propio desarrollo técnico y las transformaciones internas que tienen que ver con la regulación de los conflictos entre los grupos y de los individuos con los grupos y con el Estado, así como los conflictos que unos estados mantienen con otros a lo largo del tiempo.

\section{Más allá de los Estados impera la ley del más fuerte}

De hecho, no ha sido el estado la única forma de organización social que los hombres han alcanzado una vez que han superado, para decirlo con Morgan, el estado de barbarie, sino que los estados, a su vez han dado lugar a nuevas figuras, particularmente, a los imperios, que surgen cuando un estado se comienza a organizar como la forma del todo que integra nuevos territorios o incluso estados. Y desde el punto de vista histórico tal vez con el siglo XX y más aún en el siglo XXI se están efectivamente ensayando nuevas ideas acerca de formas de vida post-

\footnotetext{
16 Pastor, Op. Cit., pág. 45.

17 Gustavo Bueno, "Conceptos conjugados", El Basilisco, n 1, 1978; págs. 88-92.

http://www.filosofia.org/rev/bas/bas10109.htm
} 
estatales, con más o menos acierto. Existen organismos internacionales como el tribunal internacional de la Haya, o la ONU, etc., pero todas estas instituciones están hoy por hoy sometidas de hecho al poder de los estados más fuertes, dando por buena para los estados la tesis que Trasímaco defendía en La República de Platón. Entre los estados, desde luego, la ley del más fuerte es lo único que rige. ¿̇Es posible un poner supranacional? A esta cuestión, hoy por hoy, sólo podemos contestar con un sí condicional, esto es, cuando un estado o un grupo de estados se impone al resto de los estados "del mundo", por las armas. Sólo cuando una organización, como por ejemplo, la OTAN, sea capaz militarmente de someter a todas las naciones según sus planes políticos, podremos contestar afirmativamente a esta cuestión, porque un gobierno supranacional efectivo de otro modo sólo podría alcanzarse como lo pretendían cándidamente los marxistas trostkistas, esto es, cuando cada estado haya alcanzado el socialismo y se encuentre en la antesala de la súperación de la transición desde la política a "la administración de las cosas", como se solía decir.

La cuestión que se discute actualmente mucho entre los ideólogos de la izquierda, sobre todo, es la que se refiere al asunto de la existencia de poderes supranacionales, que no son exactamente políticos, pero que son capaces de dirigir a las naciones, como es el caso del llamado capitalismo financiero. Un tópico muy propio del pensamiento de izquierdas que llamamos divagante, siguiendo las enseñanzas de Gustavo Bueno en su libro El Mito de la izquierda ${ }^{18}$, es que las multinacionales financieras son ajenas a los intereses de los estados en los que surgen, y las naciones y pueblos no tienen nada que ver con ellos. Consideramos ingenua esta apreciación, habida cuenta de que la articulación de intereses entre multinacionales y estados es tal que no se entienden separados. No todos los estados hacen la pascua a los demás, ni tienen el poder suficiente para promocionar a sus empresas más allá de sus fronteras, defenderlas, o incluso convertirlas en verdaderos poderes financieros a base de derrocar gobiernos y usurpar recursos naturales, como se viene haciendo por parte de EEUU desde 1991 con la Guerra del Golfo contra Irak hasta la actual guerra civil de Siria. Otra cosa es que la "gente normal de la calle", en un país cualquiera, esté en contra de esas malvadas prácticas de sus estados, pero esto no permite concluir que los estados y las multinacionales no están involucradas sobre todo por la coincidencia de planes políticos y económicos. Así pues, por más impoluto, moderno, sofisticado, y atractivo que sea, por más elegante, moderado y canoso que sea un presidente de una institución supranacional como la ONU o del FMI, no dejará de estar al servicio de intereses nacionales, o imperiales, y ello aunque un presidente de la nación que pretende ejercer mayor poder sobre el resto reciba con todos los honores el Premio Nobel de la Paz.

\section{Estado como forma de organización universal de la vida en el presente}

Actualmente, todo hombre pertenece a algún estado, es ciudadano de alguna nación política, independientemente de que quiera o no pertenecer a ella. Los pueblos indígenas, las sociedades bárbaras que perviven hasta el presente,

18 Gustavo Bueno, El mito de la izquierda, ediciones B, Barcelona 2003.

http://fgbueno.es/gbm/gb2003mi.htm 
pueden poblar grandes territorios y reservas, pero al fin y al cabo, son ciudadanos de alguna nación política, más allá de su "nación étnica"19. No hay hombre sin estado, ni existe territorio habitado que no forme parte de algún estado. Los estados incluso se hacen cargo de su espacio aéreo, y de sus zonas marítimas. Los más poderosos se reparten territorios deshabitados del continente antártico, para llevar a cabo diferentes experimentos, pero sobre todo para ampliar su propia soberanía frente a otras naciones. Y es que los estados están en conflicto mutuo permanente. Los orígenes de estos conflictos, por supuesto, tienen que ver con cuestiones fundamentales que pocas veces se tienen en cuenta en los análisis políticos que se hacen, por ejemplo, sobre ta transición española: me refiero obviamente a la cuestión de la escasez y las carencias que todos los estados deben afrontar. No son autosuficientes. Y esta situación de desigualdad entre los estados, es una fuente constante de conflictos. Los estados nacen, de hecho, del conflicto. La conformación de las fronteras de las naciones suelen surgir de conflictos bélicos, de guerras y escaramuzas varias, que poco a poco han ido afianzando y reafirmando las diferentes fronteras. La guerra no solo es la continuación de la política por otras vías, sino también el origen mismo de la política, de las polis, de los estados. Por esta particular debilidad constitutiva de los estados, están en conflicto permanente. Ahora bien, los conflictos no siempre son susceptibles de ser soportados por los estados, por lo que parece obvio que la propia debilidad de diversos estados hace que muchos alcancen pactos y uniones que les fortalecen frente a terceros. Pero también suele ocurrir que los estados débiles se ven sometidos a la presión de otros estados más fuertes, viéndose obligados a asumir pactos e integrarse en programas que tal vez no les beneficien objetivamente, aunque al menos esto pueda garantizar un estado de equilibrio o de paz más o menos estable. Decía Rousseau que el fin de todo estado es su conservación en el tiempo todo lo posible. Y esto supone, sin duda, el sostenimiento de planes y programas capaces de hacerlos perdurar, teniendo en cuenta su particular estado de debilidad relativa frente a otros estados y su tendencia inevitable hacia la corrupción.

\section{La Historia como fundamento de la capa basal de todo Estado}

De modo que en todo estado tenemos unas fronteras que delimitan un territorio en el que vive una población organizada conforme a leyes escritas. El hecho de tener fronteras requiere por parte de los estados una capacidad de defensa del territorio, que la da el ejército, sin duda. Territorio, fronteras, y población conforman los elementos básicos de cualquier estado, por grande o pequeño que sea. Ahora bien, a estos elementos es necesario añadirles al menos otro: la historia. Cuando se afronta la historia de los pueblos se insiste en el conjunto de acontecimientos políticos que han tenido lugar, las guerras, conflictos internos y detalles de diversos tipos, pero cuando hablamos de historia de las naciones no nos referimos al conjunto de acontecimientos que jalonan su paso por el tiempo, sino a otro asunto mucho más profundo: a la conformación de su propio entramado territorial, material. Una de las propiedades objetivas de la Materia es precisamente la

\footnotetext{
19 Para estos conceptos puede consultarse el libro de Gustavo Bueno, España frente a Europa, Alba editorial, Barcelona 1999. http://www.fgbueno.es/gbm/gb1999es.htm
} 
Memoria. De todo queda rastro. Y eso mismo ocurre con el territorio. Un estado se conforma en el tiempo a través de los procesos de transformación material que los habitantes van realizando, de modo que ese territorio adquiere el aspecto de una estructura, un entramado tecnológico y productivo articulado, un entramado que acaba regulando la vida y las acciones de los individuos en ese territorio. La regulación de la vida es la que confiere un patrón diferencial que constituye lo que podemos llamar la nación política. Una nación no es un invento y no se puede establecer constitucionalmente, si no hay una intervención constante en el territorio y una transformación del mismo de modo cerrado. Porque el entramado tecnológico que llamamos "basal" está organizado de modo cerrado dentro de sus fronteras. Cuando las constituciones definen naciones y pueblos, mucho tiempo atrás ya esos púeblos y naciones han ido conformándose, y si ello no es así la situación es inestable y puede que explosiva. Es lo que ocurre por ejemplo con la instauración del estado de Israel en Palestina. Una masa de población impone un nuevo orden estatal sobre otro ya organizado y necesariamente tiene que intervenir no solamente a escala conjuntiva, a la escala de las relaciones de producción, tiene que intervenir en la transformación del territorio, poblamiento, destrucción de poblaciones anteriores, eliminación de pobladores del anterior estado, destrucción de sus infraestructuras y recomposición de otras nuevas orientadas al sostenimiento de la población hegemónica. Muros, fronteras, colonias, y destrucción del entramado basal previo, todo es poco para reconfigurar el territorio en una nueva nación.

La profundidad de la huella que se deja en el territorio define gran parte de la propia estabilidad y fortaleza de una nación política. Así, por ejemplo, diríamos que la URSS era un estado fuerte en muchos tramos de su estructura, pero su intervención en la capa basal se hizo de un modo tan apresurado que no alcanzó a la consolidación de una capa basal capaz de sobreponerse a las herencias previas de los territorios que después se alzaron como naciones a poco más de los 70 años de su existencia histórica. El entramado de la capa basal alcanzó a Rusia, quizá a Bielorusia, Kazajstan, y a la parte oriental de la actual Ucrania, pero no a su parte occidental y central, o no de manera suficiente. Por supuesto que esto no explica el fin de la URSS, pero es importante. No obstante, su intervención si dio para que de ese inmenso territorio surgieran nuevas naciones políticas más o menos capacitadas para autosostenerse. Desgraciadamente, estas naciones no son lo suficientemente fuertes para sobreponerse a la presión que puede ejercer sobre ellas Rusia, pero también son los suficientemente débiles como para convertirse en un verdadero problema para Rusia, había cuenta de que otras naciones, particularmente EEUU, están tratando de socavar el estado ruso, atacando a través de los "eslabones débiles" que la protegen, así Georgia, Armenia, Azerbaiyán, Ucrania, o Bielorrusia, y poco a poco el Imperio americano, consciente de su necesidad de expandirse por ese vasto territorio cargado de recursos y estratégicamente esencial para el dominio final del mundo, irá horadando, como un rompehielos esas plataformas estatales y rompiéndolas para abrirse paso hacia Rusia. Es cuestión de tiempo y oportunidad, porque sólo así puede atribuirse alguna finalidad al disparatado imperio del caos que ha sembrado la administración estadounidense en todo el territorio que rodea a la antigua Unión Soviética. El caos en Yugoslavia, Grecia, Ucrania, Siria, Libia, Afganistán, Irak, Palestina, Líbano, Turquía, Azerbaiyán, Georgia, todo contribuye 
poco a poco a abrir brechas que permitirán posteriormente avanzar hacia Rusia. Y en la resolución de ese conflicto está la consecución de los objetivos imperiales de EEUU.

De la misma manera, los independentismos periféricos en España que pretenden desgajar parte de su territorio tienen en la capa basal su principal dificultad, porque la capa basal de esos territorios está articulada en el contexto de la organización general de España, de manera que resulta prácticamente imposible ejercer la soberanía sobre la capa basal de territorios como Galicia el País Vasco, Cataluña o Andalucía. Y por ello mismo, se insiste en estas regiones en la capa conjuntiva, esto es, en la dimensión política y social del independentismo como ideología, como símbolo, como emoción; haciendo a lo sumo instituciones regulativas como por ejemplo "embajadas", medios de comunicación, etc., instituciones conjuntivas que no tienen suficiente fuerza para la ruptura efectiva del Estado.

\section{Sobre el carácter anómalo de la población}

El aspecto de la organización política, lo que Bueno llama la capa conjuntiva, aquella que tiene que ver con las relaciones de producción, es decir, la regulación de las relaciones que organizan la vida de las poblaciones dentro del estado sin duda afecta también a la fortaleza del estado. Pero su carácter generacional y anómalo hace mucho más difícil la sostenibilidad de los estados a escala conjuntiva si no hay una suficientemente convincente masa ideológica que sostenga la unidad política. El idioma es fundamental, eso bien lo sabemos, por eso las regiones separatistas españolas se preocupan mucho de renegar del Español y promocionar de modo oligofrénico sus idiomas locales. Pero también, los símbolos y el contexto de la interpretación histórica, la ideología envolvente en la que se forja la cosmovisión de los ciudadanos. Es más difuso y débil porque las poblaciones tienen un existir anómalo e indeterminado por las generaciones, y por el ritmo biológico de la vida. Es así como ha sido posible transformar la mentalidad de los habitantes de Cataluña desde la implantación de la LOGSE, y convertir a una importante cantidad de población en nacionalistas xenófobos, pero a esta escala conjuntiva estas situaciones son reversibles.

No obstante, es en la capa conjuntiva donde se establecen la mayor parte de los debates acerca del Estado y en donde se sitúa, seguramente, la discusión marxista del Estado, porque en ella se perfilan los gobiernos, y las instituciones regulativas de las relaciones entre los individuos, códigos, leyes, sistemas de gobierno y representación, etc. La discusión política centrada en la capa conjuntiva, sin hacer alusión a la capa basal y cortical suele dar lugar a reflexiones ideológicas y políticas formalistas que pierden por ello todo fundamento político materialista, de manera que resulta de todo punto imposible una discusión filosófica seria sobre las formas de gobierno que no tenga en cuenta la intervención y la necesidad de la presencia de la capa basal y cortical. 


\section{Sobre la fortaleza de los estados}

Si el fin de todo estado es su permanencia en el tiempo, esta permanencia sólo depende de la fortaleza de cada estado, y la fortaleza de los estados depende, sin duda, de las relaciones de producción, pero particularmente, de la consolidación de estas relaciones a través del entramado basal productivo tecnológico que conforma, canaliza y articula la vida de la población. Eso es lo fundamental. Una mayor cantidad de población, incluso juvenil y productiva, no da la fortaleza a un estado si no tiene un entramado productivo capaz de canalizar esta población: el ejemplo es China, o Bangladesh. Igualmente, si ese entramado basal deja de estar sostenido por una población decreciente, estamos igualmente ante una crisis del estado.

No obstante, la fortaleza de los estados es siempre relativa a la fortaleza de sus vecinos, y con éllos se tiene que medir y se mide necesariamente. Los estados están en permanente conflicto. Cuando su fortaleza relativa es equiparable, estamos ante equilibrios inestables, esto es lo que favorece estados de tolerancia mutua. Los estados son tolerantes entre sí en función de su fortaleza. Si son demasiado fuertes con respecto a sus vecinos pueden ser perfectamente intolerantes. Históricamente los estados más fuertes se han impuesto sobre otros, conformando situaciones de transformación histórica objetiva, en lo que suelen llamarse los imperios. No todos los imperios actúan del mismo modo y proceden con los mismos criterios de organización política, aunque en sus componentes basales coincidan. La explotación de los recursos puede hacerse de muchas maneras, y requiere una organización social que puede tener distintas perspectivas, pero en la medida en que nos referimos al trato de unas naciones con otras, unas poblaciones con otras, habría dos modos de tratar, al menos, este conflicto: cuando la población imperial entiende como inferior y explotable a la población imperiada, o cuando la población imperial se articula con la imperiada identificándose mutuamente. Esto es lo que Bueno ha definido con la distinción entre imperios generadores e imperios depredadores. El imperio de Alejandro Magno, el Imperio Romano, el Imperio español, fueron imperios generadores, el Imperio de la Unión soviética. El imperio británico ha sido un imperio depredador, el imperio belga, el imperio francés, el imperio alemán (en todas sus vertientes), y el imperio anglosajón norteamericano. También la Liga de Delos hegemonizada por los atenienses. De hecho, creo que la liga de Delos se parece peligrosamente a la OTAN, siendo la Atenas moderna EEUU, y Pericles el ideal de todo presidente norteamericano. La diferencia fundamental es que los imperios depredadores por esencia tienden a perpetuarse y crecer exponencialmente, por ello es más propio de los imperios depredadores ta destrucción de naciones. El imperio del caos que actualmente siempre EEUU por países como Afganistán, Irak, Siria, o Libia ha tenido un claro interés depredador, aunque se adorne con el discurso acerca de la democracia, pero eso no es creíble. Irak, Afganistán, Siria o Libia hubieran podido recorrer, igual que España un proceso de transición política si las políticas intervencionistas de sus respectivos gobiernos hubieran podido seguir adelante, y el propio islamismo radical hubiera sido una mera anécdota dentro de estos territorios, pero EEUU ha abandonado sus proyectos originales para entregarse a sU estrategia depredadora tal vez inspirada por megaproyectos multinacionales de alcance impreciso. Mientras que los imperios generadores responderían a un 
proceso cíclico generacional en virtud del cual, en un determinado momento de su desarrollo los nuevos territorios comienzan antes o después a organizarse de manera circular interna, y segregarse del resto, aunque ello suponga crisis y conflictos irremediables, porque nadie puede anteponerse a los procesos históricos.

\section{El caso de España}

Si analizamos el fenómeno de la transición española desde la perspectiva de la teoría del estado que ofrece Gustavo Bueno en su importante obra, Primer ensayo sobre las categorías de las "ciencias políticas", creo que podemos extraer algunas interesantes precisiones que no se suelen tener en cuenta en los estudios tradicionales. Al fin y al cabo, el tema de la transición sólo se enfoca desde un punto de vista político, y ello, en efecto, contribuye a ocultar importantes aspectos de España, que simplifican y convierten en leyenda la transición como una especie de estado de gracia de España.

España es un país resultante de ese proceso de desmembramiento de un imperio generador, el imperio español. De su matriz surgieron diferentes naciones políticas, entre ellas España; que es el país que se instituyó como forma del todo durante el proceso de su despliegue como imperio. Nadie responda a la pregunta de por qué fue imperio, si no contesta simplemente, "porque pudo hacerlo", pues otra razón no hay más profundamente histórica. Es muy difícil hablar de voluntad de Estado, de Imperio, pero el ortograma del catolicismo es el que canaliza esa pujanza histórica que adquiere el reino de Castilla. Está claro que el siglo XIX y todos sus conflictos están en relación con la destrucción de esa idea que guiaba a la nación desde tiempos de los Católicos. El fin del imperio supone una reorganización sangrienta de la nación, plagada de intentos y proyectos en conflicto que desembocaron en un período histórico magnífico, la llamada Edad de plata, en la que se alcanzó de algún modo el renacimiento de la nación española ya como nación canónica, replegada a sus fronteras "naturales", una vez que la guerra con EEUU desmembró los últimos territorios nacionales ultramarinos. Ese período sin embargo no consiguió estabilizar los conflictos que se realimentaron con las nuevas ideologías fascistas y marxistas, dando lugar a la Guerra civil española. El triunfo de Franco significó la reorganización objetiva de la nación española conforme a una idea de unidad de estilo francés, basada en el desarrollo del entramado productivo basal, un desarrollo inusitado y eficaz. Durante ese período se alcanzó una reorganización efectiva de toda la trama basal del estado, una actualización sistemática de los factores productivos y una modernización productiva generalizada de la nación.

El resultado de la guerra permitió el fortalecimiento del estado, con empresas públicas muy poderosas para la distribución de la energía, transportes y comunicaciones, la industria extractiva y de transformación. De esta manera España llegó a 1975 como un estado fortalecido por la propiedad pública de los factores productivos fundamentales, y con unos índices de desarrollo extraordinarios. El cambio de régimen es, como dice Bueno, una metamorfosis de esa propia crisálida. Pero el sistema político español se orientó de un modo perverso. En gran medida el fin del período de Franco está marcado por una cada 
vez más ostensible debilidad, a consecuencia de una clara definición del relevo político y una enorme presión exterior de países como EEUU, y los países europeos como Francia o Alemania, que ven con recelo la fortaleza de este estado. Todos ellos intervienen, pero particularmente EEUU. Antes de nada arrebata Marruecos a España la provincia del Sáhara, con aprobación norteamericana. El rey necesita consolidar su poder, y ello será a costa de la nación. Los partidos políticos nacientes necesitan consolidar su poner, y ello también será a costa de la nación. Demasiadas fuerzas actúan sobre España con intereses contrapuestos, lo que contribuye a su debilitamiento ostensible.

Dice Eslava Galán en su libro Historia de España contada para escépticos ${ }^{20}$ que a partir de los años setenta comienza a actuar en nuestra historia un nuevo factor que él prefiere llamar simplemente "el gran hermano". Y así es. Desde la muerte de Carrero Blanco, hasta el Golpe de estado de Tejero, así como otros luctuosos acontecimientos que han jalonado la historia reciente de España, encontramos siempre la sombra de una duda, que resulta preocupante. Pero sin echar culpas a nadie, lo acontecido responde claramente a un programa bastante preciso que consiste, fundamentalmente, en el debilitamiento sistemático del estado. Un debilitamiento que permite en primer lugar la entrada en la OTAN y en la Unión europea, hasta la entrega irreversible que supone la renuncia a la soberanía monetaria con la entrada en el marco-euro. El debilitamiento se ha producido, sin duda, en la capa basal mediante un desmantelamiento sistemático. La reconversión industrial permitió la privatización y el cierre de gran parte de la industria nacional; la entrada en la Unión europea, y el tratado de Maastricke supuso la renuncia por parte de España a su propia cabaña ganadera, la reconversión del sector agrario y pesquero. Se privatizaron las empresas nacionales de energía eléctrica (con la consabida puerta giratoria), y las de telecomunicaciones, las empresas energéticas, transportes como lberia, industrias tan solventes y poderosas como la fábrica Pegaso, o Seat, vendidas a empresas extranjeras, y particularmente la industria siderúrgica. En aquellas primeras y salvajes oleadas se argumentaba siempre sobre la base de que la privatización mejoraría los servicios y haría más rentables las empresas, y por tanto, resultarían más baratos los servicios prestados, pero nada de eso era cierto y, aunque lo fuera a corto plazo, a la larga los españoles nos veríamos privados de la fortaleza necesaria para afrontar nuestro destino político.

La entrada en la Unión europea trajo consigo una inflamación del cuerpo del estado con dinero rápido y fácil, que enriqueció a los españoles disolviendo poco a poco su capacidad de resistencia. Es el mecanismo de las arañas que tienen que tragarse una presa demasiado voluminosa. Le insuflan los jugos gástricos primero, antes de comerse a la víctima, y cuando el cuerpo está licuado, simplemente se lo beben poco a poco. Así ocurrió con España en Europa. Se nos inundó de dinero a golpe de financiación y subvenciones para paliar el cierre sistemático de empresas nacionales, de industria extractiva, y de industria pesada y media. Todo iba bien. Parecía que la reconversión no nos afectaba, cada vez vivíamos mejor, y trabajábamos menos. Programas de prejubilación, y bancos cada vez más agresivos facilitaban el dinero líquido y vivíamos, como dicen los

20 Juan Eslava Galán, Historia de España contada para escépticos, Planeta, Barcelona 2004. 
políticos, por encima de nuestra posibilidades. El sistema de banca pública que en España era muy poderoso y había jugado un papel esencial en la organización productiva del país durante el franquismo, comenzó a privatizarse poco a poco a favor de bancos privados. El banco de Bilbao se hizo con la Caja Postal, el banco público que repartía el salario de todos los funcionarios del estado durante muchos años, y que por supuesto no facilitaba la posibilidad de que algún banco privado pudiera lucrarse en los mercados financieros con la gestión de estos sueldos. Argentaria fue el instrumento de transición hacia la privatización. Hoy por hoy, todos los funcionarios reciben su dinero en su banco desde el banco de Bilbao, y en los mercados financieros cada segundo cuenta. Las cajas se entregaron a los políticos regionales que hicieron de ellas su propio negocio hasta que la gestión politizada hizo que todos deseáramos que se privatizaran.

Muchas de las grandes empresas estatales que todavía perduran han eliminado a sus funcionarios, reconvertidos en personal laboral, evitando con ello que por su naturaleza pública se evite cualquier tipo de presión contra los trabajadores. Ahora tampoco la naturaleza pública de una empresa garantiza la estabilidad laboral, y menos aún la independencia del criterio del funcionario. Volvemos poco a poco hacia el viejo sistema clientelar, hoy reconvertido y purificado por los mass media. Y todos nos alegramos de que los funcionarios públicos sean reducidos en sus condiciones laborales, "porque es una injusticia".

La reconversión en la capa basal ha sido tremenda, ha permitido la entrada masiva de multinacionales que se han hecho con los despojos del estado y que han reducido las condiciones laborales, endurecido la explotación y la inestabilidad, la desigualdad, y el abuso de poder. Han debilitado al estado. Las multinacionales ahora apelan a la deslocalización y en el mercado mundial el trabajo de los españoles vale menos que nada, por lo tanto, se puede explotar y reducir sus garantías laborales hasta límites insospechados hace algunos años. Como el estado no tiene fuerza para bloquear esta presión de las multinacionales, y no tiene capacidad para afrontar la renacionalización de sectores estratégicos o simplemente no tiene programa político alguno que se atenga a estos sanos preceptos consistentes en el fortalecimiento del estado, los españoles no tenemos capacidad ni individualmente ni en sindicatos o partidos para afrontar las oleadas de explotación laboral y precariedad en el empleo que caen sobre nosotros como el maná del cielo de las finanzas internacionales. En el proceso de privatización de las empresas públicas se ha llegado incluso a declarar el estado de alarma (2010), por parte de Rubalcaba y Zapatero, para hacer frente a la huelga de controladores aéreos que protestaban contra la privatización de AENA. Tales fueron los intereses en conflicto en esta operación financiera el gobierno no dudó en intervenir a escala militar para facilitar la privatización hoy ya realizada, mientras que los trabajadores de AENA, y los controladores aéreos en particular, se convirtieron poco menos que en monstruos dispuestos a destruir la felicidad de nuestros compatriotas que necesitaban a toda costa viajar a sus lugares de vacaciones para seguir siendo felices mientras que estos aguafiestas paraban a capricho el tráfico aéreo en el "puente de la Constitución" precisamente. Una vergüenza.

En el proceso de transición, faltaba atacar a la capa cortical y conjuntiva. Faltaba reconvertir a la sociedad, eso era en principio cuestión de tiempo, de cambio 
generacional. Y se hizo muy bien. Se aprovechó la circunstancia de la adustez, respetabilidad, sacrificio y capacidad de trabajo, responsabilidad de nuestros mayores, la generación de nuestros padres y abuelos, para ir abriendo el camino a la democracia con la ilusión de la libertad sin ira. Y fue bueno, pero nadie entendía entonces que la libertad sin ira era sobre todo, la libertad sin fuerza, sin tejido productivo, la libertad neoliberal. De momento era solo la libertad sin ira, y los españoles obviamente votaron sí. Pero ahora había que ir abriendo nuevas brechas y sobre todo evitar que nos diéramos cuenta de que bajo nuestros pies alguien segaba nuestra libertad esquilmando nuestro tejido productivo nacional. Era necesario que fuéramos mirando hacia otra parte: y así nació la movida madrileña, el gran escaparate de escapismo y buen rollo que nos despistó mucho a todos los jóvenes que no habíamos caído en el abismo de la heroína que pululaba a raudales por ahí, desahuciando vidas a mansalva. Por si fuera poco con estas salvas cargadas de rock and rollo, del buen rollo british que nos mostraba el Mike Jagger de turno, pagado por sus enormes servicios a la City de Londres con el nombramiento como caballero británico. A mí siempre me gustó el Rock, sin embargo, reconozco que no pude por menos de sonrojarme cuando vi en la ceremonia de relevo de las Olimpiadas de Pekín al guitarrista de Led Zeppelin, Jimmy Page tocar con su guitarra aquel tema de Whole Lotta Love, comprendiendo casi de golpe la importancia que el Rock ha tenido como disolvente de la soberanía nacional. Claro que en China resultaba tan ridículo que daba vergüenza ajena, y al mismo tiempo uno se sentía en cierto modo estafado, ahora nos dábamos cuenta de qué iba todo aquello del Sex, and Drugs and Rock and Roll, el gran ortograma anarco-neoliberal anglosajón. También producía cierta sensación de ridículo: qué podían pensar los chinos viendo semejante escena. Pensarían acaso: zes así como el imperio anglosajón se ha comido todas las tostadas? Pues casi sí. Bien fácil ha sido.

Y cuando esto ya no era suficiente, vino la gran revolución cultural que supuso la LOGSE a primeros de los años noventa. La LOGSE eliminó sistemáticamente lo poco que quedaba en la capa conjuntiva de un modelo de estado basado en la necesidad de la fortaleza productiva. Algunos simplemente lo llamaban una reforma educativa para evitar el modelo desarrollista franquista que quería formar trabajadores al servicio de Franco. Tonterías: lo importante era eliminar la formación profesional y se hizo bien. Se adujo que era una vergüenza que se discriminara a los jóvenes por su capacidad, que todos eran iguales y todos debían tener el mismo sistema educativo, la temible ESO. "Y si te va mal estar sentado en un pupitre seis horas al día durante cuatro años, pues estás cinco, o seis, y si tienes dificultades te ponemos un psicólogo, o dos, o tres, uno para cada uno si hace falta, con el fin de mantenerte en el sistema. Si luego a los 16 años, o 17, ya bien cargado de frustración y abatimiento quieres hacer un módulo de grado medio, ya puedes, pero antes, la ESO. Y no contestos con eso, para evitar que la discriminación fuera mayor, si luego querías pasar a un módulo de grado superior, debes pasar por el bachillerato. Esta última barbaridad se ha atenuado últimamente, pero el sistema es igual. La ESO son cuatro años para todos. Se eliminaron todos los centros de formación profesional, se les obligó a integrarse en la ESO, se eliminó el cuerpo de profesores de Formación Profesional, se equipararon todos los cuerpos, porque todo aquello era discriminatorio. Siempre sobre el prejuicio ideológico absurdo según el cual la formación profesional en un 
oficio era algo peyorativo, frustrante y denigrante, que generaba una sociedad desigual e injusta. ¿̇Qué queda de esa palabrería hoy, cuando la desigualdad ha aumentado a límites intolerables, la precariedad laboral campea, y los trabajadores además reciben una formación nefasta?

En la LOGSE primaban otros criterios. No formamos a trabajadores que sostengan el entramado productivo de un estado fuerte, sino a ciudadanos que buscan la felicidad, y cuyo fin último es ser felices, como dice el intragable Marina una y otra vez. La felicidad personal, la satisfacción, el sentirse bien, estar a gusto, disfrutar de la vida, olvidarse de los problemas, gozar. Lo otro era condenar a los españoles a una vida austera dedicada al trabajo al servicio del gran Leviatán. Ahora lo cambiamos por sentirse bien, aunque tu libertad quede reducida a tu libertad personal individual Vale. (En uno de los últimos capítulos de El Ministerio del Tiempo, se especúla sobre la posibilidad de que Felipe II se hubiera convertido en emperador no solamente del espacio y su tiempo, sino también del futuro, y cómo sería la vida de los españoles entonces. Resulta interesante ver qué modelo de vida se habría establecido, según los guionistas.)

El otro gran factor de reconversión de la capa conjuntiva vino del sector audiovisual. Aquí se produjo, como en el resto de los sectores productivos una transformación brutal y muy definida. Es lo que relata Sidney Lumet en Network: un mundo implacable. Una película de 1976 que aborda el asunto de la transformación de la televisión en EEUU, cuando la audiencia y el éxito económico se imponen sobre el ideal de servicio público que todavía perduraba en las cadenas de televisión. William Holden y Faye Dunawey caracterizan respectivamente dos modos de entender la televisión en conflicto. El respetable periodista, maestro de periodistas, que defiende la responsabilidad del medio televisivo como un servicio público, y la empresaria agresiva capaz de inventarse un nuevo modelo televisivo (que por cierto es el que está establecido en la Sexta, en España, sin ninguna duda) basado en el espectáculo, en la búsqueda de audiencia y en la persecución de las ganancias, sobre la consigna que Charles Foster Kane dejó establecida en Ciudadano Kane: cuando el viejo director del Inquirer se quejaba porque se estaban publicando noticias de "comadres", que no tenían importancia, Kane le responde, si la noticia va en portada se hace importante. La Sexta hace lo mismo. Utiliza el descontento, lo azuza, lo amplifica, se regodea en él desde todos los puntos de vista, con el único fin de aumentar la audiencia y mantener a los televidentes pendientes de rasgarse las vestiduras unas cuantas veces a diario, a la hora de comer, de cenar, y después de comer, y después de cenar, y a cualquier hora, con sátiras "guayóminas", o con debates teatrales, da lo mismo.

El último gran hito en el proceso de desarticulación del estado en su entramado productivo, era ya la capa cortical, y esta tuvo dos grandes etapas. La primera, cuando el Golpe de estado de Tejero reforzó el poder del rey que para sostenerse en su trono necesitaba el apoyo sistemático de EEUU, y por ello o por gusto, no se sabe, o por prudencia "monárquica", quería entrar en la OTAN a toda costa, incluso haciendo dimitir a Suárez, que nunca quiso que España entrara en la OTAN, cuando aun España era suficientemente fuerte para decir que no, pero Suárez 
dimitió (esto lo dice Pilar Urbano ${ }^{21}$ ), y el golpe de estado dio permiso al rey para entrar en la OTAN. Con ello, de entrada, ya la capa cortical quedaba mediatizada por poderes militares internacionales y la debilidad del estado era más que notoria. Pero aun teníamos la milicia nacional, todos los jóvenes españoles iban a la "mili", y allí se hacían cargo de que algo de la defensa de la patria tenía que ver con las escopetas y la marcialidad militar. Pero el movimiento de objeción de conciencia, alimentado por la ideología de la felicidad personal, y el individualismo liberal, junto con el ideal del buen salvaje roussoniano y la doctrina marxista y anarquista del fin del estado represor, de fuerza arrolladora, llevó a una situación que aunque hubiera podido resolverse de otro modo, se resolvió del modo más inesperado y solvente: Aznar eliminó la "mili", profesionalizó el ejército y ahora mismo su estructura nacional está totalmente entretejida por el entramado militar de la OTAN como fuerza bélica defensiva de los intereses occidentales en general, europeos en particular, y verdaderamente correspondientes con los planes generales del imperio de EEUU y sus diversas estrategias internacionales: Irak, Afganistán, Libia, Siria, Yugoslavia, Rusia... La eliminación de la milicia nacional fue recibida con júbilo por todos los españoles que ya no tenían el más mínimo interés por pasar un año haciendo el tonto en un cuartel, mientras que podían dedicar ese año a disfrutar de la felicidad en cualquiera de sus modos magníficos de ser consumida con un poquillo de la pasta que venía de Europa a raudales.

Lo último ya es ver cómo funciona todo este mecanismo. Ahora que hemos convertido a la nación española en una marioneta anclada por los temibles hilos de acero de las multinacionales, la moneda única marco-euro, los bancos privados y el sistema financiero internacional, y la OTAN; ahora que la tenemos amarrada por los cuatro costados, vamos a ver cómo se comporta. Montamos una crisis financiera y procedemos a extraer a manos llenas de ese país toda su riqueza, porque a todo van a contribuir los diferentes gobiernos de turno, entregados ya a la lógica de no hacer nada que atente contra los intereses del capital. La debilidad del estado es también la debilidad moral de nuestra sociedad.

La privatización va alcanzando paradójicamente los ideales a los que aspiraba el marxismo y el anarquismo en su doctrina del fin del estado. Efectivamente, la disolución del entramado productivo nacional favorece el debilitamiento del estado, que cada vez, como en un círculo vicioso, irá perdiendo más fuerza. Incluso, las nuevas ideologías de la izquierda neoliberal pedirán la desaparición del aparato represor del estado, esto es: la policía, la guardia civil y el ejército, con el fin de contribuir a la disolución del estado represor, dando cabida así a la universalización de las iniciativas privadas de seguridad que ya se llevan ensayando muchos años. La privatización sistemática, de hecho, favorecerá la posibilidad del desmembramiento de la capa basal del estado, precisamente aquello que por ahora sostiene la efectiva y material unidad territorial del Estado, por lo que los intereses de los partidos independentistas, más si son de izquierdas divagantes, pero también si son de derechas, por razones obvias, coincidirán con los intereses de las multinacionales, y aun de otras naciones, a costa de la libertad

21 Pilar Urbano, La gran desmemoria, Planeta, Barcelona 2014. 
y la soberanía de España. Esos intereses pueden coincidir o pueden actuar conjuntamente, mientras que el Estado pierde poco a poco capacidad de intervención para sostener la soberanía nacional.

Cuando todo esté preparado, el acuerdo TTIP traerá consigo el fin de eso a lo que se aferran los socialdemócratas "más radicales": Ios servicios públicos, la educación y la sanidad. Como si eso fuera lo único para lo que debe servir el Estado. Pero bien, incluso esos servicios quedarán disueltos en el proceso de privatización y disolución del Estado, y esto, obviamente, también interesa al secesionismo. La debilidad del Estado es también la debilidad de la sociedad que acaba convirtiéndose a su vez en eso a lo que aspiran las ideologías divagantes de la izquierda: una sociedad civil, disuelta, sin fuerza, sin dominio propio, sin soberanía sobre su territorio y su destino. Que ya no tendrá nada sobre lo que decidir y cuyas decisiones no tendrán trascendencia alguna en el destino de la sociedad. Es el credo que Jeremy Rifkin, el asesor de Clinton, puso de moda para los ideólogos de la socialdemocracia europea, en su libro El fin del Trabajo 22: Ios Estados deben desaparecer en aras de la sociedad civil, el tercer sector, la voluntad de servicio de las personas que por voluntad anarquista quieren ayudar, pero todo ello, articulado por el implacable dominio de la única verdad recogida en las bombas que tiran los aviones de la OTAN allí donde haya la más mínima resistencia.

En definitiva, la privatización del entramado productivo trae consigo la debilidad manifiesta del estado, y con ella, su dependencia del exterior. De hecho, en la visita que Obama ha hecho a España este verano ya se puede observar que su papel no es el de representante de un estado amigo, sino el de emperador visitando sus colonias. EEUU garantiza, en palabras de su presidente, la unidad de España, si y sólo si, seguimos proporcionándole territorio y cobertura para el despliegue de su estrategia imperial en Occidente. Desde sus bases militares recibe, pues, a los representantes políticos españoles, conscientes hoy más que nunca de su secundario papel en cualquier proceso político en España.

Y este es el resultado más vistoso de la transición española: un estado debilitado y dependiente, entregado a la soberanía europea y norteamericana, cuyo destino y unidad sólo están garantizados por el interés que nuestro país hegemónico tenga en conservarlo como tal. Ciertamente, el contexto geopolítico tal vez excluyera cualquier otra posibilidad, porque los países que se han resistido a la presión imperial no han tenido precisamente buena suerte, y tal vez la prudencia política ha dirigido de modo menos traumático nuestro destino presente teniendo en cuenta cómo se comportan los ejércitos de la OTAN y las cosas que han ocurrido por aquí. Pero dentro de los márgenes que la prudencia política nos permite, creo que los partidos políticos españoles no han tenido en cuenta las más mínimas y discretas razones prudenciales que permitieran, dentro de los márgenes que se nos ofrecen, mantener una mínima dignidad nacional, tal vez por eso definirse como españoles resulte ser hoy prácticamente clandestino y disidente.

Benavides de Órbigo, 4 de agosto de 2016

22 Jeremy Rifkin, El fin del trabajo, Paidós ibérica, Barcelona 2010. 